\title{
Pragmática e discurso: a noção de texto em questão
}

Bruno Deusdará

\section{Resumo}

No presente artigo, temos como objetivo discutir a noção de texto, a partir das contribuições da pragmática e seus desdobramentos em uma perspectiva discursiva. Inicialmente, destacamos uma diversidade de caminhos que caracterizam a disciplina pragmática. Em seguida, explicitamos algumas das reflexões de Searle (2010), destacando seus limites para uma concepção de texto. Recuperamos a proposta de Maingueneau (1996), segundo a qual os atos de fala devem ser considerados no conjunto dos gêneros do discurso a que pertencem. Por fim, a partir de observações sobre os dois textos de mídia, ressaltamos o vínculo entre a dimensão textual e o ato de base que lhe dá sustentação.

Palavras-chave: Análise do discurso. Pragmática. Gêneros do discurso. Texto.

\section{Considerações iniciais}

Os debates em torno da noção de texto têm atravessado abordagens de natureza tanto textual, quanto discursiva e são aqui indicados como elemento que parece confirmar a produtividade das diversas iniciativas de sua conceituação. Entre essas abordagens, a recusa da autonomia do texto - ilusória unidade conferida por sua limitada extensão material é marca de perspectivas discursivas, para as quais o sentido da linguagem é instável e produzido no embate entre discursos - remissão constante a outros discursos, construindo relações de oposição, aliança, ou aparente neutralidade. Essa remissão de um discurso a outros,

* Professor do Programa de Pós-graduação em Letras (área de concentração em Linguística). Professor Adjunto do Departamento de Estudos da Linguagem (Instituto de Letras) e do Departamento de Línguas e Literatura (Instituto de Aplicação) - UERJ. E-mail: brunodeusdara@gmail.com

Data de submissão: abr. 2013 - Data de aceite: ago. 2013 http://dx.doi.org/10.5335/rdes.v9i2.3852 
diferente do que sugeriram as primeiras versões da noção de intertextualidade, não é concebida como partindo de uma unidade visível e prévia e apontando para seu exterior, igualmente composto de unidades fechadas em suas próprias fronteiras. $\mathrm{O}$ primado do interdiscurso será ressaltado como condição de existência dos discursos, cuja delimitação é provisória, recortando-os nessa massa de discursos que constituem uma determinada conjuntura. O projeto assim configurado é o de "subverter essa equivalência entre o exterior do discurso e o interdiscurso, para pensar a presença do interdiscurso no próprio coração do intradiscurso" (MAINGUENEAU, 2005, p. 38).

Observa-se, nesse tipo de abordagem, uma delicada articulação entre as noções de texto e discurso. Não sendo tal articulação o foco prioritário dos debates a serem empreendidos no presente artigo, parece-nos possível aceitar que o texto seja concebido como a face material dos discursos. Ressalte-se, no entanto, que essa formulação sustenta-se somente se nela não se cristalizarem oposições como a que suporia que o texto representaria fechamento e unidade, enquanto ao discurso caberiam as ideias de abertura e dispersão. Ao ganhar materialidade, um texto não pertence a um único discurso, mas oferece pistas que remetem a posicionamentos distintos. Dessa forma, uma questão importante para esse tipo de abordagem reside em interrogar de que modo o dito institui-se, agenciando os implícitos, os não ditos, tomando a materialidade textual como pista que permite recuperar sentidos outros, cofigurando posicionamentos em embate.

Com efeito, o que se afirma aqui é uma trajetória de conceituação da análise do discurso $(\mathrm{AD})$ que passa por lutas frente ao conteudismo, que supunha poder "alcançar uma pretensa significação profunda, um sentido estável, conferido pelo locutor no próprio ato de produção do texto" (ROCHA; DEUSDARÁ, 2005, p. 307). A referência a uma 'significação profunda' anuncia uma oposição que caracterizou esse modo de conceber as trocas verbais imaginando haver uma profundidade que se oculta por uma superfície textual, impedindo o acesso direto a essa camada interna. No contexto dos anos 1960, a recusa da autonomia dos textos, a partir de um enfoque discursivo, inseria-se nessas lutas, propondo que as pistas materiais oferecidas pelos enunciados só podem produzir sentido por remeter à enunciação. Contrapunha-se, assim, à crença na "possibilidade de ultrapassar as 'aparências', os níveis mais superficiais do texto, residindo nesse processo de descoberta a desconfiança em relação aos planos subjetivo e ideológico" (ROCHA; DEUSDARÁ, 2005, p. 309-310).

A esse respeito, Maingueneau ressalta a contribuição de uma pragmática, referida genericamente por ele, na tentativa de "inscrever a atividade da linguagem em espaços institucionais” (1997, p. 29), o que não havia sido observado até então 
pelos estudos do discurso. Lançamo-nos aqui na problemática relação entre pragmática e análise do discurso cuja tensão entre fronteiras parece-nos fornecer uma discussão produtiva para a reflexão proposta a respeito da noção de texto, e essa será a ênfase dada neste artigo.

Referimo-nos a uma problemática relação, por observar que, por vezes, esse encontro é concebido como uma rivalidade: "A pragmática é o verdadeiro Outro da AD", assevera Possenti, "por mais que também combata as gramáticas formais e universais, que se afaste das sociologias da linguagem e das semânticas lógicas, seu [da AD] verdadeiro adversário é a pragmática" (POSSENTI, 2004, p. 363).

O que se observa na discussão acima é que, de um lado, faz-se referência genérica a uma pragmática que teria contribuído com o aprimoramento das formulações no que tange a uma dimensão institucional das práticas de linguagem e, de outro, constrói-se um simulacro dela, que se constitui como principal adversário da $\mathrm{AD}$. A nosso ver, a explicitação dos aspectos que se constituem como pontos importantes no desenvolvimento das reflexões atuais, bem como os elementos considerados como pontos a serem combatidos pode oferecer uma trajetória produtiva para aqueles que optam por orientações discursivas em sua prática de pesquisa.

A sequência das reflexões propostas exige-nos uma explicitação acerca dos usos que o termo pragmática assume aqui. Quando se faz referência ao termo pragmática, não se pode ignorar, no entanto, a diversidade de usos que o caracterizam. Considerando seu valor instável, Charaudeau e Maingueneau (2004), no verbete pragmática, registram três acepções: como subdisciplina da linguística; como corrente de estudo do discurso; e ainda, como concepção de linguagem.

A primeira acepção pode designar um componente da linguagem, ao lado do componente semântico e do sintático. Quanto ao caráter disciplinar da pragmática, Charaudeau e Maingueneau (2004) mencionam a posição daqueles que pretendem ver nela uma subdisciplina da linguística ${ }^{1}$, à qual caberia a recusa da ideia de que os sentidos seriam provenientes apenas de um conteúdo linguístico, em favor de sua ancoragem no contexto. Entre os diferentes pesquisadores habitualmente inseridos nessa disciplina, "todos estão basicamente de acordo sobre o fato de que a interpretação de um enunciado não pode levar em consideração apenas a informação linguística, não contextual" (CHARAUDEAU; MAINGUENEAU, 2004, p. 394). Destaca-se ainda uma terceira acepção do termo, ao caracterizar uma dada concepção de linguagem que não nega sua dimensão representacional, mas acentua seu caráter de intervenção sobre o mundo.

Na discussão exposta no presente artigo, propomos reflexão acerca da noção de texto, quando se assume uma concep- 
ção de linguagem como forma de ação. Formulando dessa maneira, tal propósito mantém com o território disciplinar da pragmática certo grau de aproximação, sem, contudo, confundir-se com ela. Para o debate a ser desenvolvido aqui, é importante explicitar um caminho de reflexão acerca do que ganha materialidade linguística e os implícitos. Considerar como fundamental o agenciamento entre o verbal e seu entorno é elemento que, de um lado, aproxima a $\mathrm{AD}$ de uma concepção de linguagem como forma de ação e, de outro, torna a pragmática seu principal adversário.

Desse modo, atenta-se à contribuição que a teoria dos atos de linguagem dará para superar a cisão fundamental entre o "dizer" e o "dito", no âmbito dos estudos da linguagem. Sem dúvida, diversos têm sido os esforços nesse sentido do encontro entre a filosofia e os estudos da linguagem na discussão relativa a uma concepção pragmática de linguagem, procurando ressaltar certos aspectos vinculados a uma compreensão acerca do texto. A relevância crescente que vem sendo conferida à pragmática é o ponto de partida para a presente discussão, investindo fundamentalmente em uma abordagem mais ampla, que tem interessado aos estudos do discurso, perspectiva com a qual temos trabalhado.

Partimos, portanto, de uma explicitação da diversidade de percursos que caracteriza a disciplina pragmática, centrando-nos em um modo muito particular de concebê-la, aquele proposto por Searle (2010), em que se faz um grande esforço no sentido de evidenciar possíveis convergências entre a perspectiva de Austin/Searle e Grice. Em seguida, enfocamos a noção de atos de fala, retomando algumas das propostas que estiveram vinculadas a essa noção. Indicamos também algumas das críticas que são feitas, em especial, à proposta de Searle e a insuficiente análise dos atos isolados. Na sequência, recuperamos a proposta de Maingueneau (1996), segundo a qual os atos de fala devem ser considerados no conjunto dos gêneros do discurso a que pertencem. Por fim, a partir de observações acerca de dois textos de mídia, ressaltamos o vínculo entre a dimensão textual e $o$ ato de base que lhe dá sustentação.

\section{Perspectiva pragmática: percursos, propostas e impasses}

$\mathrm{Na}$ impossibilidade de acompanhar um percurso único para a disciplina pragmática, propomos, como eixo para este item, discutir sobre a compreensão em torno da significação na linguagem, a partir da perspectiva sustentada por Searle.

Ao assumir que a história do conhecimento constitui-se não por tradições, ou grandes períodos, mas por descontinuidades, a proposta que ora apresentamos ao leitor pretender centrar-se em um texto de Searle, em que o autor parte de um aparente distanciamento entre 
a perspectiva de P. Grice e a aquela dos atos de fala, atribuída a J. Austin e a ele próprio e pretende constituir pontos de contatos, em que seja possível evidenciar convergências, mais do que dissensos.

Optou-se pelo referido texto, pois esse permite articular aspectos diversos. De um lado, acompanhar a própria argumentação de Searle a respeito do trabalho de P. Grice e perceber todo o seu esforço conciliatório em funcionamento. Por outro, tal opção permite-nos igualmente incluir a relação ambígua que Searle mantém com o pensamento de Austin, bem como as polêmicas decorrentes dessa relação. $\mathrm{O}$ que ficou razoavelmente estabelecido, nos manuais de filosofia da linguagem, é a versão que segue sintetizada nas palavras de Marcondes: "Searle considera que Austin não forneceu princípios ou critérios suficientemente claros para a sua classificação dos atos" (MARCONDES, 2005, p. 23). Apenas para indicar ao leitor o tipo de crítica que a versão proposta por Searle da teoria dos atos de fala veio recebendo, Derrida (apud RAJAGOPALAN, 2010) afirmou que a grande contribuição de Austin residiria menos nas classificações efetivamente alcançadas do que na tentativa constante em que investiu. A potência de uma perspectiva pragmática viria mais da afirmação dos usos de linguagem como ato do que da justeza de suas grades classificatórias.

Antes, porém, é necessário indicar minimamente contornos dos percursos da disciplina pragmática, apontando certa diversidade de orientações que a caracteriza, além de ressaltar a pluralidade de sentidos atribuídos ao termo "pragmática". Vejamos o que um dicionário de Filosofia diz a respeito:

Uma das partes da semiótica e precisamente a que compreende o conjunto das investigações que têm por objeto a relação dos sinais com os intérpretes, isto é, a situação em que o sinal é usado. Sobre este aspecto da semiótica haviam já insistido C. S. Pierce e Ogden e Richards; mas foi particularmente Morris que considerou a P. [pragmática] como parte integrante da semiótica; e o ponto de vista de Morris é amplamente aceito na lógica contemporânea (cf. C. Morris, Foundations of The Theory of Signs, 1983, cap. V; CARNAP, Foudantions of Logic and Mathematics, 1939, § 2). As outras partes da semiótica são a semântica e a sintaxe (ABBAGNANO, 1982, p. 752).

$\mathrm{O}$ verbete acima reafirma o que se encontra amplamente divulgado pela literatura das áreas da filosofa e da linguística: o texto fundador a que se atribui o gesto de delimitar a pragmática como campo específico é Foundation of the theory of signs, de autoria de C. Morris e publicado originalmente em 1938. A emergência da pragmática, como uma corrente filosófica, remonta assim à crise do pensamento filosófico de fins do século XIX. Esse cenário de emergência será definido por Paveau e Sarfati (2006), do seguinte modo:

A conjuntura era então de uma tripla problematização das matemáticas (Cantor descobre a presença de antinomias nos sistemas axiomáticos; Godel estabelece a incompletude da lógica), da lógica clássica (o debate que opõe Frege a Husserl e a Bretano marca o recuo do psicologismo e anuncia a pesquisa de uma linguagem e de um método 
capazes de garantir a objetividade das proposições) assim como da metafísica tradicional (ela se traduz pelo questionamento das construções especulativas herdeiras e, sob a influência do Círculo de Viena, produziu um discurso de justificações da atividade humana) (PAVEAU; SAFARTI, 2006, p. 215).

Com isso, destaca-se o fato de que o surgimento da pragmática no horizonte de uma filosofia da linguagem está muito pouco relacionada ao cenário da linguística, com a qual parece manter trajetória paralela, com poucos pontos de contato. Na sequência, Paveau e Safarti indicam o que consideram um problema terminológico para qualificar os campos em questão. Sugerem os autores, como alternativa ao referido problema, assumir uma designação genérica para o termo pragmática, tomado como um “domínio de estudos, sem especificação de um objeto de pesquisa a priori". Resguardando-se a expressão pragmática filosófica, para designar "seja o fato de que a pragmática deriva historicamente da filosofia", "seja os projetos de refundação das grandes questões da filosofia (conhecimento, moral, política...) a partir das aquisições da filosofia analítica”, e pragmática linguística para referir-se ao "conjunto das teorias elaboradas, no quadro da linguística, a partir da integração dos conceitos e perspectivas de trabalho da filosofia da linguagem ordinária". Os autores reservam ainda um quarto termo pragmática da linguagem "para designar o conjunto de modelos de tipo pragmático que tomam como objeto de estudos diferentes aspectos da lingua- gem não articulada (especialmente os sistemas culturais enquanto sistemas integrantes de comunicação)" (PAVEAU; SAFARTI, 2006, p. 217).

Percebe-se que o problema terminológico é constantemente acionado quando ele retorna em outros autores. Ao lado da definição proposta por Morris, registre-se outra, atribuída a Anne-Marie Diller e François Récanati, mais estritamente linguística: “a pragmática 'estuda a utilização da linguagem no discurso e as marcas específicas que, na língua, atestam sua vocação discursiva" (ARMENGAUD, 2006, p. 11).

As distinções terminológicas acima referidas interessam-nos aqui por apresentarem diferentes apreensões dos problemas demandados pela delimitação de um componente da linguagem que se ocupa de seu uso em situação concreta. Nesse sentido, o que se reteve da proposta de Morris foi a distinção entre a pragmática, como disciplina auxiliar que trataria do uso da linguagem pelos falantes, e a semântica, que se ocuparia do conteúdo dos enunciados, com base na noção de condições de verdade (MAINGUENEAU, 1996).

Outro aspecto criticado por Morris interessa-nos em particular, pois demonstra incoerências da visão dicotômica que separa enunciado e contexto. Isso se exemplifica na ênfase dada por ele aos chamados elementos indiciais, que, a partir de Jakobson, passam a receber a denominação embreantes. Esses elementos serão fundamentais, na medida 
em que apontam sempre para uma interpretação que articule o enunciado com a situação em que foi produzido.

Até aqui reunimos alguns elementos que já nos permitem indicar que, se há algo que parece consensual entre os pragmaticistas, tal aspecto centra-se na abordagem da significação como processo que se viabiliza por instruções fornecidas por pistas materiais inscritas nos enunciados. Mais uma vez, observa-se aqui a necessidade de reflexão, como a que ora propomos, acerca da noção de texto, como dimensão material das trocas verbais em situação concreta.

A partir de agora, trataremos especificamente da noção de atos de fala. Para isso, discutiremos a proposta de Searle cujo propósito é articular concepções aparentemente inconciliáveis. A opção por Searle deve-se justamente às críticas que têm sido atribuídas ao modo como esse autor reivindicou espaço frente às reflexões de Austin. "Se, por um lado, Searle goza de todo um prestígio por desenvolver a teoria dos atos de fala, por outro, ele se mostra igualmente ávido por afirmar uma fácil continuidade entre Austin e ele próprio, apesar de todas as diferenças" (RAJAGOPALAN, 2010, p. 92). A ênfase conferida aos dissensos na reconstrução de uma perspectiva teórica pretende justamente que não se perca a potência do pensamento que a funda, em detrimento das trajetórias lineares oferecidas pelos manuais, em que se apagam as polêmicas ou as organizam em caminhos dicotômicos, nos quais se silenciam as multiplicidades.
Partindo do pressuposto pragmático de que a linguagem é uma forma de ação, Austin vai interessar-se inicialmente por verbos performativos, isso é, aqueles que alteram a realidade pela sua própria enunciação. Diante dessa categoria, um enunciado não pode figurar entre as noções de verdadeiro ou falso, mas sim de eficácia ou não da ação provocada por ele. Esses verbos performativos estariam em oposição aos constativos, que descrevem um estado de mundo, mantendo autonomia frente à enunciação.

A esse respeito, os manuais registram o que teria sido sua primeira formulação:

Austin avança uma primeira hipótese: as línguas naturais se organizam em torno de uma distinção funcional entre dois tipos de enunciados (com exceção do sem-sentido): os enunciados constativos que descrevem um estado de coisas (como no exemplo 1) e os enunciados performativos, que permitem realizar um certo tipo de ação (como no exemplo 2):

(1) O céu está azul

(2) Eu prometo resolver esse problema

Os enunciados do tipo (1) são verdadeiros ou falsos, na medida em que eles dão ou não dão conta de um estado de coisas objetivo [...] e obedecem a condições de verdade (empiricamente observáveis). Os enunciados do tipo (2) não são nem verdadeiros nem falsos, mas susceptíveis de serem 'felizes' ou 'infelizes' (eles exprimem um engajamento do locutor, ou qualquer outro tipo de intervenção) (PAVEAU; SAFARTI, 2006, p. 218). 
Um segundo movimento teórico de Austin registrado pelos manuais reside na impossibilidade que o próprio autor teria observado na distinção entre verbos performativos e verbos constativos. Não haveria momento em que enunciados estivessem comprometidos apenas com uma descrição do mundo, sem implicar necessariamente uma ação sobre o outro. É a partir de então que o referido autor propõe a categoria de atos de linguagem. Dessa noção resulta que qualquer enunciação teria uma força ilocutória que se articularia com seu conteúdo proposicional.

Nessa reformulação de Austin de sua categorização inicial, ao abandonar a oposição constativo / performativo e perceber que há uma força ilocutória em todos os enunciados, é preciso ressaltar que a linguagem passa a ser definitivamente considerada como uma forma de ação. Dessa maneira, aquela que já foi considerada heteróclita e multiforme assume um caráter de objeto científico, sobretudo pelo viés da pragmática.

Tudo o que se disse anteriormente a respeito da teoria dos atos de fala elaborada por Austin já nos indica uma forte compreensão de uma dimensão institucional subjacente aos usos de linguagem. Tal compreensão aponta para a significação como remetendo à situação empírica. De acordo com Searle, aqui residiria um ponto de distanciamento entre P. Grice e a teoria dos atos de fala de Austin/ Searle. Para Grice, a intencionalidade individual é noção importante para a teoria dos atos de fala. O significado é criado "por atos individuais mediante os quais os falantes tentam causar efeitos nos ouvintes, fazendo-os reconhecer sua tentativa de causá-los" (SEARLE, p. 231). Já segundo a formulação teórica desenvolvida por Austin e os desdobramentos propostos por Searle confere destaque ao "papel das instituições sociais na realização dos atos de fala" (SEARLE, p. 232). O significado "não é só um produto da intencionalidade individual, mas também resultado de práticas sociais" (SEARLE, p. 232).

Conforme destacou Searle, apresentadas dessa forma as duas abordagens referidas acima seriam apenas aparentemente irreconciliáveis. $\mathrm{O}$ que nos interessa aqui é acompanhar a opção feita por Searle para argumentar favoravelmente à possibilidade de integração de perspectivas que foram admitidas como concorrentes.

O primeiro movimento de Searle passa por indicar que ambas as perspectivas supõem distinguir uma "intenção de comunicar" de uma "intenção de representar", já que, segundo o autor, a representação de um dado estado de coisas implicado em um ato de fala não estaria necessariamente obrigado a comunicar nada a alguém, como parece ilustrar o exemplo a seguir: "quando afirmo para você que está chovendo, há uma distinção entre minha intenção de representar afirmativamente o estado de coisas de estar chovendo e minha intenção de comunicar essa representação a você" (SEARLE, p. 233). 
Com base nessa distinção, a intenção de representar determina a força e o conteúdo do ato de fala. Já a intenção de comunicar estaria relacionada ao propósito de reconhecimento do interlocutor do ato que se propõe, já que "a intenção de comunicação é simplesmente que o ouvinte reconheça a enunciação e reconheça que ela tem as condições de satisfação que o falante pretende que tenha" (SEARLE, 2010, p. 241). Do modo como está formulada, essa distinção parece atribuir papel destacado à intencionalidade, tornando a interação um encontro fortemente enraizado em uma compreensão racional do que se realiza entre os indivíduos. Um esvaziamento das forças em embate observa-se, por exemplo, em observações como a que considera que "a comunicação bem-sucedida consiste no reconhecimento das intenções de significação do falante" (SEARLE, 2010, p. 241).

$\mathrm{O}$ excessivo destaque conferido ao papel da intencionalidade nas situações de interação verbal conduzirá a um enfraquecimento de uma reflexão institucional das práticas de linguagem. Tal opção levará o autor a considerar que a intenção de representar é anterior à de comunicar, porque "alguém não pode sequer ter a intenção de comunicar, a menos que tenha uma força ilocucionária e um conteúdo proposicional que pretenda comunicar", "não há comunicação sem representação" (SEARLE, p. 235).

Esse encaminhamento para integração das perspectivas em embate levará Searle a afirmar que a dimensão insti- tucional dos atos de fala desdobra-se, segundo Searle, em três aspectos: i) a realização de um ato de fala envolve essencialmente fatos institucionais. ii) os fatos institucionais pressupõem sistemas de regras constitutivas. iii) o mesmo sistema de regra é invocado por diferentes línguas (SEARLE, 2010).

As tentativas sucessivas de estabelecer critérios pormenorizados de listagem dos atos de fala, que caracterizam a contribuição de Searle, é fortemente inspirada pela premissa de que haveria algo de universal neles: "uma análise completa também exige que se reconheça a existência de habilidades e práticas de fundo que capacitam os seres humanos a de algum modo se comunicar ou ter estados intencionais" (SEARLE, 2010, p. 247).

A incorporação da teoria dos atos de fala a uma concepção que se estrutura em torno do problema dos universais não escapou de críticas severas. Tornar secundário o caráter circunstancial da linguagem, que permitiu afirmar um potencial de criação de real dos atos verbais, tem sido compreendido como um esforço de domesticação do pensamento de Austin:

A tentativa de Searle de aerodinamizar esses pensamentos e recolocá-los no trilho debilitado da filosofia analítica foi mais do que bem-vinda, foi uma intervenção providencial que salvou a comunidade filosófica de ter de tolerar um membro ilustre que ameaçava tornar-se um empecilho (RAJAGOPALAN, 2010, p. 81). 
A primeira consequência do tipo de opção realizada pelo autor: produção de uma imagem ideologicamente bem delimitada de sujeito ao qual a teoria dirige-se.

Para a teoria dos atos de fala, o sujeito da linguagem é um agente inteiramente racional, que sempre tem controle sobre seus pensamentos e decisões, que é educado nos maneirismos da classe média (especialmente dos EUA) - polidez ('Seria muito gentil de sua parte se você pudesse...'), boas maneiras à mesa ('Você poderia me passar o sal, por favor?'), e todo o resto (RAJAGOPALAN, 2010, p. 132).

Outra consequência: enfraquecimento de uma perspectiva institucional, justamente o que havia sido considerado como contribuição importante da pragmática para os estudos do discurso: "Todos os atos de fala que pressupõem instituições extralinguísticas, como declarar que tais pessoas são marido e mulher, declarar guerra, adiar uma reunião e assim por diante, pressupõem regras constitutivas" (SEARLE, 2010, p. 248).

Pressupor instituições extralinguísticas às quais os atos de fala estariam vinculados é algo que já se observava em Austin. A dimensão institucional subjacente aos atos de fala é inspirada na cena jurídica, cuja origem permanece sem qualquer tipo de questionamento por Searle. Ao contrário, a sugestão de que as regras corresponderiam a padrões universais produz um abrandamento de toda uma reflexão que poderia conduzir a considerações sobre o social como criação conjunta entre um plano da linguagem e seu entorno.
Uma evidência do retrocesso representado por Searle diante do impasse acerca da tentativa de elaborar uma genealogia das "instituições extralinguísticas" encontra-se no fragmento que segue, no qual o social é pensado quantitativamente:

As capacidades sociais de que estamos falando só existem nas mentes dos agentes individuais, dos falantes individuais numa sociedade. São sociais no sentido de que seu funcionamento exige e pressupõe o contato com diferentes agentes na sociedade. Mas isso de maneira nenhuma impede que se realizem inteiramente nos cérebros individuais (SEARLE, 2010, p. 252).

A perspectiva assumida por Maingueneau representa um avanço considerável em relação a esse tipo de reflexão, em que se acentua apenas a autorreferencialidade dos atos, apagando-se a própria força de produção de real implicada nesses atos: “... as condições de satisfação da ordem não são somente que a coisa ordenada seja feita, mas sobretudo que seja feita porque foi ordenada", ou seja, "o que a ordem ordena é que ela mesma seja obedecida” (SEARLE, 2010, p. 240).

Dessa forma, uma reflexão sobre a noção de texto já nos parece bastante insuficiente, como correlato das consequências apontadas anteriormente. $\mathrm{O}$ texto é compreendido como produto da intencionalidade do sujeito falante, passando a compreensão pelo reconhecimento dessa intencionalidade presente no texto e de ações correlatas reconhecendo explicitamente tal intencionalidade. O equívoco é percebido como não satisfação das condições de realização do ato de linguagem. 
Apagam-se as forças em embate que ganham expressão na materialidade verbal. Uma alternativa possível para esse achatamento da noção de texto parece ter sido indicado por Maingueneau (1996), quando prefere considerar não atos de fala isolados, mas assumir os gêneros do discurso como macroatos de linguagem.

\section{Gêneros do discurso como macroatos de linguagem}

No item anterior, desenvolvemos uma série de discussões que pretendem evidenciar que o trabalho de Searle não é apenas um desdobramento da teoria dos atos de fala, de Austin, mas antes oferece uma nova configuração para o que se persegue como proposta de sistematização. A distinção entre uma intenção de representação e uma intenção de comunicação já demonstra o peso excessivo conferido a uma dimensão informacional da linguagem, em detrimento do seu potencial de produzir encontros, viabilizar outras configurações de real.

Reconhecendo a importante contribuição da noção de atos de fala, Maingueneau (1996) ressalta, no entanto, a impossibilidade de a leitura guiar-se diretamente por esses. Ao contrário, cada ato parece ter seu caráter percebido no interior de um gênero do discurso. Essa ampliação do ato de fala como uma dimensão sociohistórica que atravessa os enunciados é preocupação que se desdobra também na noção de "gêneros do discurso", elemento importante integra- do a uma dada concepção pragmática de linguagem. Trata-se de considerar que:

Quando nos interessamos não por enunciados isolados, mas por textos, como é o caso da literatura, não é possível nos contentarmos em trabalhar com atos de linguagem elementar (prometer, predizer...). A pragmática textual é confrontada com sequências mais ou menos longas de atos de linguagem que permitem estabelecer num nível superior um valor ilocutório global, o dos macroatos de linguagem (MAINGUENEAU, 1996, p. 14).

O que Maingueneau (1996) chama de macroatos de linguagem são, na tradição bakhtiniana, os gêneros do discurso. Apenas para recuperar a clássica definição de gêneros do discurso, retomamos aqui a citação de Bakhtin: "[...] cada esfera de utilização da língua elabora seus tipos relativamente estáveis de enunciados" (2000, p. 279). Observe-se que em tal definição privilegiam-se os vínculos entre utilização da língua e a estabilidade dos tipos de enunciados.

$O$ linguista francês o intitula como macroato para evidenciar a profunda relação que há entre o gênero e tudo o que se tem desenvolvido a partir das contribuições da pragmática. Assim, é preciso dizer que os enunciados não existem de forma isolada em uma situação de uso, o texto é a unidade da interação verbal. Por isso, os gêneros discursivos encontram-se em uma ordem superior ao valor ilocutório de enunciado, porque esses valores terão intensidade maior ou menor, poderão ser compreendidos de forma distinta, dependendo do gênero em que estiverem inseridos. 
Maingueneau afirma que:

A problemática dos gêneros revela-se portanto crucial aqui; a partir do momento em que identificou a que gênero pertence um texto, o receptor é capaz de interpretá-lo e comportar-se de modo adequado a seu respeito (MAINGUENEAU, 1996, p. 15-16).

Em oposição aos modelos informacionais em que o locutor assume uma posição ativa, como emissor de uma dada mensagem, enquanto o interlocutor apenas a recebe, a partir da noção de gênero do discurso, compreende-se a troca verbal como espaço de coprodução entre os parceiros, ambos, locutor e interlocutor, em "atitude responsiva ativa":

[...] o próprio locutor como tal é, em certo grau, um respondente, pois não é o primeiro locutor, que rompe pela primeira vez o eterno silêncio de um mundo mudo, e pressupõe não só a existência do sistema da língua que utiliza, mas também a existência dos enunciados anteriores - emanantes dele mesmo ou do outro - aos quais seu próprio enunciado está vinculado por algum tipo de relação. (BAKHTIN, 2000, p. 291).

Com isso, Bakhtin afasta-se de modelos mais tradicionais que poderiam ver 0 linguístico apenas como algo que subjaz às trocas, dotado de um funcionamento autônomo, ou ainda, compreendendo o social como uma força que agiria de fora para dentro. De acordo com o referido autor, podemos pensar o linguístico e o social como territórios moventes, que se interpenetram, produzindo sentido.

Desse modo, os estudos do discurso viabilizariam certo modo de analisar pontos nodais nessa complexa rede que atravessa as práticas de linguagem na constituição do social.
Cada época e cada grupo social têm seu repertório de formas de discurso na comunicação socioideológica. A cada grupo de formas pertencentes ao mesmo gênero, isto é, a cada forma de discurso social, corresponde um grupo de temas (BAKHTIN, 1992, p. 43).

A partir da citação acima, observa-se que as diferentes dimensões do discurso encontram-se articuladas, não sendo possível privilegiar um plano da informação em detrimento dos demais aspectos que constituem os gêneros. Desse percurso, é possível destacar uma reflexão sobre a noção de texto, conforme já o havíamos indicado:

Paradoxalmente, o texto é dimensão em que se atualiza uma realidade convencional, anterior a ele, como condição de sua existência e circulação, ao mesmo tempo em que só tem sentido por constituir-se através de processos de singularização. Ou seja, os movimentos de sentidos próprios ao texto transitam entre a repetição e a diferença (DEUSDARÁ; GIORGI, 2008, p. 83).

Na perspectiva defendida por Maingueneau (2013), a noção de gêneros do discurso será apreendida a partir de cinco critérios: i) uma finalidade reconhecida; ii) lugares legítimos para os parceiros; iii) coordenadas de tempo e espaço; iii) formas de circulação; iv) certa configuração textual; v) recursos linguísticos específicos. Com isso, afirma-se que os gêneros caracterizam dispositivos comunicacionais, já que propõe ruptura com um modelo linear.

Antes de passarmos à leitura do cartaz que segue, gostaríamos de apresentar ao leitor a seguinte formulação, 
em que Maingueneau propõe uma articulação entre os gêneros do discurso e os textos gerados por esses: "um texto pertence a um gênero de discurso, do qual ele é o traço; de modo recíproco, todo gênero de discurso produz um texto" (MAINGUENEAU, 2012, p. 109). $\mathrm{O}$ mérito da citação anterior reside em considerar uma dinâmica circular nessa difícil articulação entre gêneros e textos.

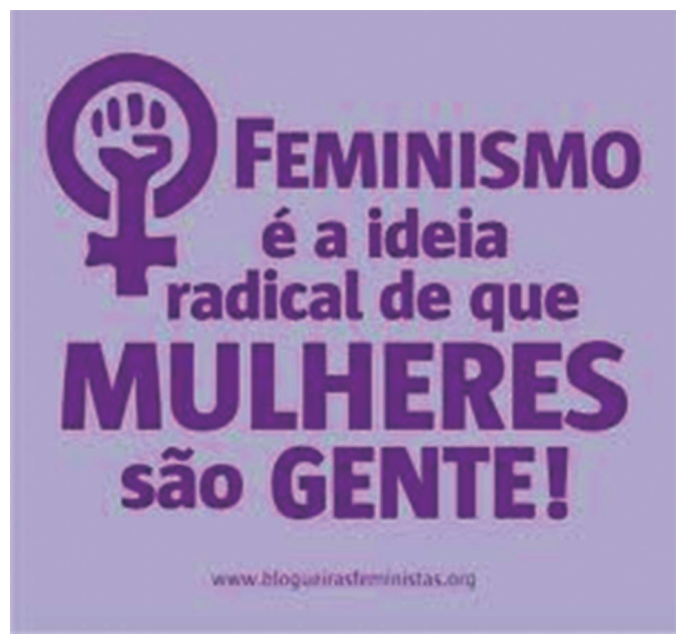

(http://blogueirasfeministas.com)

A escolha do cartaz acima não é gratuita, antes nos permite perceber que os sentidos produzidos pelo texto não estão fundamentalmente inscritos na materialidade verbal. Acrescente-se a isso o fato de que não é possível ler esse texto sem, de certo modo, participar de uma luta, na qual se denuncia a permanência de práticas machistas, em pleno século XXI, e simultaneamente se considera tal permanência como uma espécie de irracionalidade. Apenas uma pequena parte disso se institui como dito.
Um primeiro aspecto a ser observado dirige-se ao gênero do discurso cartaz, cuja finalidade aponta para a divulgação de ideias, a partir da explicitação de um ponto de vista. Considerando-se os lugares estabelecidos para os coenunciadores, um cartaz pressupõe alguém que deseje divulgar ideias ou produtos e um outro que pode ser visto como alguém, em princípio, neutro que possa aderir a essas ideias. Além disso, prevê, diríamos, secundariamente, certo embate entre os favoráveis e os contrários. O modo como esse debate é tratado no cartaz acima não se reduz a informações trazidas pelo verbal. A escolha da cor lilás já anuncia uma espécie de tomada de posição, que é igualmente reforçada pela referência ao símbolo do feminino - um círculo em cima de uma cruz, que remetem à deusa grega Afrodite - que aparece em uma releitura, cujo círculo é preenchido por uma mão fechada, sugerindo um investimento em militância social, no caso em questão, feminista. Esses elementos são ratificados pelo próprio nome da página eletrônica de origem: blogueiras feministas. Ao assumir posição flagrantemente parcial, explicita-se o diálogo com um outro, seu opositor.

Vejamos como são apresentadas as vozes em embate. O emprego do vocábulo "radical" é pista da presença de seus opositores: aquele que diz que o feminismo é radical. $\mathrm{O}$ uso dessa palavra explicita uma avaliação a respeito da ideia de que "mulheres são gente", que gera estranhamento em função da obviedade 
do que se supõe radical. A ironia reside nesse confronto entre o que se supõe ser "radical" e um já sabido a esse respeito, como obviedade.

O tom jocoso, promovido pela ironia, contrapõe-se ainda ao esperado modo incisivo de afirmação de identidade feminina. O combate proposto não se reduz ao dito. É preciso observar o modo de dizer. Aquele que censura o feminismo contrapõe-se a obviedades.

Esta ideia vincula-se ao fato de que o que precisa ser estudado são os direitos e obrigações que se assumem a cada ato de linguagem, ou seja, a cumplicidade que vincula um enunciador e ao coenunciador. Ao ser proferido, um ato de linguagem constitui uma dinâmica de lugares entre as partes envolvidas. Se ordeno algo, por exemplo, coloco meu interlocutor no lugar de alguém que se compromete com aquela ordem.

É interessante perceber também que ninguém passa antes em revista das condições de proferimento de um ato de linguagem, diferente do que parecia sugerir Searle. O próprio fato de enunciar já ocorre na pressuposição de que as referidas condições estão reunidas. Para não aceitá-las, o coenunciador precisa reagir.

A esse respeito, Deleuze e Guattari elaboram a noção de "palavras de ordem":

Chamamos palavras de ordem não uma categoria particular de enunciados explícitos (por exemplo, no imperativo), mas a relação de qualquer palavra ou de qualquer enunciado com pressupostos implícitos, ou seja, com atos de fala que se realizam no enunciado, e que podem se realizar apenas nele.
As palavras de ordem não remetem, então, somente aos comandos, mas a todos os atos que estão ligados aos enunciados por uma 'obrigação social (DELEUZE; GUATTARI, 2005, p. 16).

Vejamos a seguir o segundo texto que inspira a discussão aqui proposta:

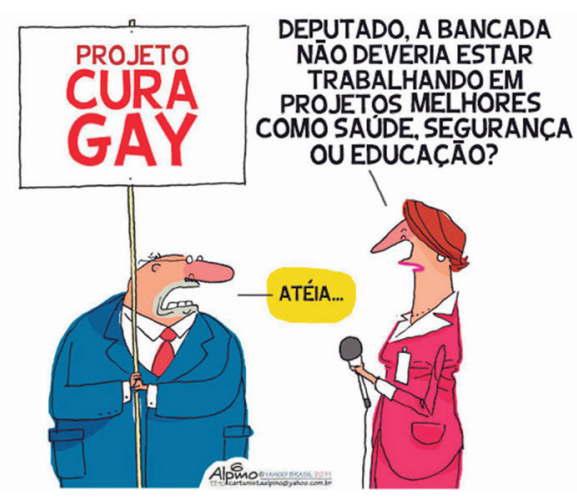

(http://blogueirasfeministas.com)

Com relação ao gênero de discurso charge, de forma diversa do que ocorre com o cartaz, seu discurso não é explícito, ao contrário, vincula-se a contextos, em geral políticos e temporalmente próximos, que dependem diretamente da relação dos interlocutores com o contexto histórico no qual são produzidos os textos para que os sentidos construam-se. As charges possuem certa dinâmica de consumo muito semelhante à das notícias, sua inscrição na atualidade é aspecto fundamental para a compreensão das vozes que são captadas e transformadas.

É interessante iniciar pela observação de que os sentidos produzidos pela totalidade da charge passam por uma compreensão da cena construída, ou seja, 
o chargista não fala diretamente ao seu leitor. Tem-se acesso à crítica proposta por meio de uma observação do modo como a entrevista realiza-se, recuperando as cristalizações do já conhecido a respeito dela e subvertendo parte dos sentidos captados.

O tema da charge é apresentado ao leitor por meio do destaque conferido à placa que o parlamentar carrega: "Projeto cura gay". Essa indicação permite recuperar os embates em torno de projetos de lei em tramitação no Congresso Nacional que, ora pretendem assegurar igualdade de diretos, como indica a proposta de união civil igualitária, ora impõem restrições, sugerindo que profissionais de saúde tratem a opção sexual homoafetiva como doença a ser curada. Identifica-se por meio da expressão "cura gay" e da resposta "ateia", proferida pelo deputado, um embate entre os que defendem e os que são contrários ao projeto de Decreto legislativo 234/11, de autoria do deputado João Campos (PSDB-GO), presidente da Frente Parlamentar Evangélica, que tem como objetivo reverter dois artigos instituídos em 1999 pelo Conselho Federal de Psicologia, que proíbem emitir opiniões públicas ou tratar a homossexualidade como um transtorno.

Em uma cena de entrevista, pressupõe-se uma dinâmica entre os coenunciados em que a um deles cabe a elaboração das perguntas e ao outro, suas respostas. Tal dinâmica já institui certa relação de poder: à jornalista compete elaborar perguntas que tenham relevância social, constituindo para ela certo lugar de representante da opinião pública. Já ao entrevistado, o próprio convite a uma entrevista o coloca na oposição de alguém que teria minimamente mais informação a respeito da temática tratada. Tal pressuposto confere ao entrevistado lugar de voz autorizada a pronunciar-se sobre determinado assunto.

Na cena construída pela charge, a pergunta da jornalista traz como pressuposto a existência de certa hierarquia entre projetos, alguns seriam "melhores" do que outros. Essa pergunta é prontamente recebida como um juízo acerca do projeto defendido pelo deputado. $\mathrm{Na}$ reação do parlamentar, a cor do balão de fala, as feições do personagem e ainda o fato de a resposta não manter relação direta com a pergunta, sugerem certo tom de indignação. No contexto acima, a resposta "ateia" é claramente uma ofensa à jornalista. No entanto, não seria suficiente identificar a reação agressiva do parlamentar à jornalista. É preciso observar que tal resposta a transforma em membro de um grupo frontalmente oposto ao seu. Ao tomar a pergunta como ofensa e responder de modo agressivo, fazendo inferências a respeito das opções religiosas da jornalista, confere-se ao parlamentar certo traço de intolerância. A crítica apresentada pela charge a respeito do projeto de lei em questão só é possível com base em uma compreensão acerca da dinâmica da entrevista, compreendendo não apenas o que cada um diz, mas os lugares propostos para cada um ao dizer. A atitude crítica que se espera ver reconhecida na charge 
passa exatamente por considerar que o referido projeto de lei é autoritário e indesejável. Tais sentidos não estão de forma alguma sendo construídos como informação, mas antes se instituem pelo ato do parlamentar, agressividade no tom e intolerância no tipo de resposta, que emerge como acusação.

Sem dúvida, há consequências importantes de uma reflexão pragmática sobre a linguagem que nos fazem insistir em suas contribuições. Segundo Deleuze e Guattari (2005), três consequências importantes:

1) A impossibilidade de conceber a linguagem como um código, visto que este é a condição que torna possível uma explicação; e a impossibilidade de conceber a fala como a comunicação de uma informação: ordenar, interrogar, prometer, afirmar, não é informar um comando, uma dúvida um compromisso, uma asserção, mas efetuar esses atos específicos imanentes, necessariamente implícitos; 2) A impossibilidade de definir uma semântica, uma sintaxe ou mesmo uma fonemática, como zonas científicas que seriam independentes da pragmática [...] a pragmática se torna, ao contrário, o pressuposto de todas as outras dimensões, e se insinua por toda parte; 3) A impossibilidade de manter a distinção língua-fala [...] são o sentido e a sintaxe da língua que não se deixam definir independentemente dos atos de fala que ela pressupõe (DELEUZE; GUATTARI, 2005, p. 14-15).

Ao tratar de um posicionamento implicado ao tomar a palavra, Passos e Barros (2009) referem-se à política da narratividade "como uma posição que tomamos quando, em relação ao mundo e a si mesmo, definimos uma forma de expressão do que se passa, do que acontece" (PASSOS; BARROS, 2009, p. 151).
Optamos pela designação "política do dizer", ampliando a reflexão acima não apenas para movimentos narrativos, mas para qualquer ato de linguagem. Com essa noção de política do dizer, o que se pretende destacar é a performatividade implicada ao tomar a palavra. Abre-se a possibilidade de relacionar essa dimensão performativa do dizer com o que vimos afirmando em torno da experiência no capítulo anterior

[...] o que interessa pensar toda experiência como emergindo de uma experimentação, pois a experiência não concerne ao que já está aí como dado inelutável, mas antes à emergência de alguma mudança [...]. Assim, se há dado, esta se constitui na experiência e não poder ser concebido antes do ato de experimentar (PASSOS; EIRADO, 2009, p. 126).

Essa indissociabilidade entre texto e ato que lhe dá sustentação acaba por relativizar o papel destacado de uma competência linguística universal em favor do caráter circunstancial das trocas verbais. Tais reflexões acerca das práticas de linguagem implicam-nos uma abordagem que põe os atos como dimensão que instaura sentidos. A linguagem seria mais performance do que capacidade:

[...] ela [a especificidade da linguagem humana em relação àquela animal] consiste, isso sim, e em medida certamente não menos decisiva, no fato de que, único entre os seres vivos, o homem não se limitou a adquirir a linguagem como uma capacidade entre outras de que é dotado, mas fez dela a sua potência específica, ou seja, na linguagem ele pôs em jogo a sua própria natureza (AGAMBEN, p. 79). 


\section{Considerações finais}

Neste artigo, valemo-nos da intensificação que vem sendo possível observar em torno da pragmática, no campo dos estudos da linguagem, como possibilidade de propor reflexões a respeito da noção de "texto", tal como pode ser possível pensar com base na máxima da linguagem como forma de ação. Tal empreitada já indica, de saída, dois aspectos das discussões que pretendemos propor aqui. $\mathrm{O}$ primeiro deles reside em observar que se trata de noção distante de consensos. $O$ segundo ressalta que nossa preocupação não passa por circunscrever um lugar institucional para a pragmática, a partir do qual pretendemos enunciar. Trata-se de investir em uma concepção pragmática de linguagem como possibilidade de repensar alguns conceitos com os quais os pesquisadores do campo dos estudos linguísticos lidam cotidianamente.

Um texto institui-se, configurando fronteiras instáveis, já que, de um lado, apresenta-se como materialidade circunscrita a limites visíveis, por outro, remete incessantemente a outros textos, atribuindo lugares distintos para as vozes que agencia.

Todo texto supõe um ato ao qual remete, instituindo as coerções necessárias à sua compreensão. Uma política da linguagem permite apontar para uma revisão da clássica dicotomia sistema / uso.
Pragmatique et discours: mettant en debat la notion de texte

\section{Résumé}

Dans cet article, nous cherchons à discuter de la notion de texte, à partir des contributions de la pragmatique et ses conséquences dans une perspective discursive. Au départ, nous mettons en évidence la diversité des trajectoires qui caractérisent la discipline pragmatique. Ensuite, nous mettons l'accent sur certaines des réflexions de Searle (2010) en témoignant leurs échecs en ce qui concerne la notion de texte. On releve le projet Maingueneau (1996), selon lequel les actes de parole doivent être pris en compte dans l'ensemble des genres de discours auxquels ils appartiennent. Enfin, on analyse deux textes médiatiques, mettant en évidence le lien entre le texte et l'acte de la base textuelle qui le soutient.

Mots-clés: Analyse du discours. Pragmatique. Genres de discours. Texte.

\section{Nota}

1 Essa posição é atribuída a MOESCHLER, J. REBOUL, A. Dictionnaire encyclopédique de Pragmatique. Paris: Seuil, 1994.

\section{Referências}

ARMENGAUD, F. A pragmática. Trad. de marcos Macionilo. São Paulo: Parábola, 2006.

BAKHTIN, M. Estética da criação verbal. Trad. de Maria Ermantina Galvão. São Paulo: Martins Fontes, 2000. 
. Marxismo e filosofia da linguagem. Tradução de Michel Lahud e Yara F. Vieira. São Paulo: Hucitec, 2004.

CHARAUDEAU, P. \& MAINGUENEAU, D. Dicionário de análise do discurso. Coord. da tradução de Fabiana Komesu. São Paulo: Contexto, 2004.

DELEUZE, G.; GUATTARI, F. Mil Platôs: capitalismo e esquizofrenia, v. 2. Trad. de Ana Lúcia de Oliveira e Cláudia Lúcia Leão. São Paulo: Ed. 34, 2005.

DEUSDARÁ, Bruno. Fazendo planos para a educação: políticas do dizer e processos de subjetivação. 2011. 266 f. Tese (Doutorado em Psicologia Social) - Instituto de Psicologia, Universidade do Estado do Rio de Janeiro, Rio de Janeiro, 2011.

DEUSDARÁ, B.; GIORGI, M. C. Práticas de linguagem como atividade social: o linguista frente ao desafio de apreender os diferentes modos de habitar o mundo. Signum. Estudos de Linguagem, v. 11, p. 75-93, 2008

MAINGUENEAU, D. Texto, gênero de discurso e aforização. Trad. de Ana Raquel Motta. In: BRAIT, B.; SOUZA-E-SILVA, M. C. (Orgs.). Texto ou discurso? São Paulo: Contexto, 2012. p. 109-128.

. Doze conceitos em Análise do Discurso. Org. de Sírio Possenti e Cecília Souza-e-Silva. São Paulo: Parábola, 2010.

. A análise do discurso e suas fronteiras. Matraga, Rio de Janeiro, v. 14, n. 20, p. 13-37, jan./jun., 2007.

Gênese dos discursos. Trad. de Sírio Possenti. Curitiba: Criar Edições, 2005.

Análise de textos de comunicação. Trad. de Cecília P. de Souza-e-Silva, Décio Rocha. 6. ed. ampl. São Paulo: Cortez, 2013.

. Novas tendências em análise do discurso. Trad. de Freda Indursky. Campinas: Pontes; Ed. Unicamp, 1997.
. Pragmática para o discurso literário. Tradução de Marina Appenzeller. São Paulo: Martins Fontes, 1996.

MARCONDES, D. A pragmática na filosofia contemporânea. Rio de Janeiro: Jorge Zahar, 2005.

ROCHA, D.; DEUSDARÁ, B. Análise de conteúdo e análise do discurso: aproximações e afastamentos na (re)construção de uma trajetória. Alea, Rio de Janeiro, v. 7, n. 2, dez. 2005.

PASSOS, E.; EIRADO, A. do. Cartografia como dissolução do ponto de vista do observador. In: PASSOS, E.; KASTRUP., V.; ESCÓSSIA, L. (Orgs.). Pistas do método da cartografia: pesquisa-intervenção e produção de subjetividade. Porto Alegre: Sulina, 2009. p. 109-130.

PAVEAU, A. M.; SAFARTI, G. E. Grandes correntes da linguística: da gramática comparada à pragmática. Trad. de M. R. Gregolin et al. São Carlos: Claraluz, 2006.

POSSENTI, S. Teoria do discurso: um caso de múltiplas rupturas. In: BENTES, A. C.; MUSSALIM, F. (Orgs.) Introdução à linguística: fundamentos epistemológicos. v. 3. São Paulo: Cortez, 2004. p. 353-392.

RAJAGOPALAN, Kanavillil. A nova pragmática: fases e feições de um fazer. São Paulo: Parábola, 2010.

SEARLE, John R. Consciência e linguagem. Trad. de Plínio Junqueira Smith. São Paulo: Martins Fontes, 2010. 